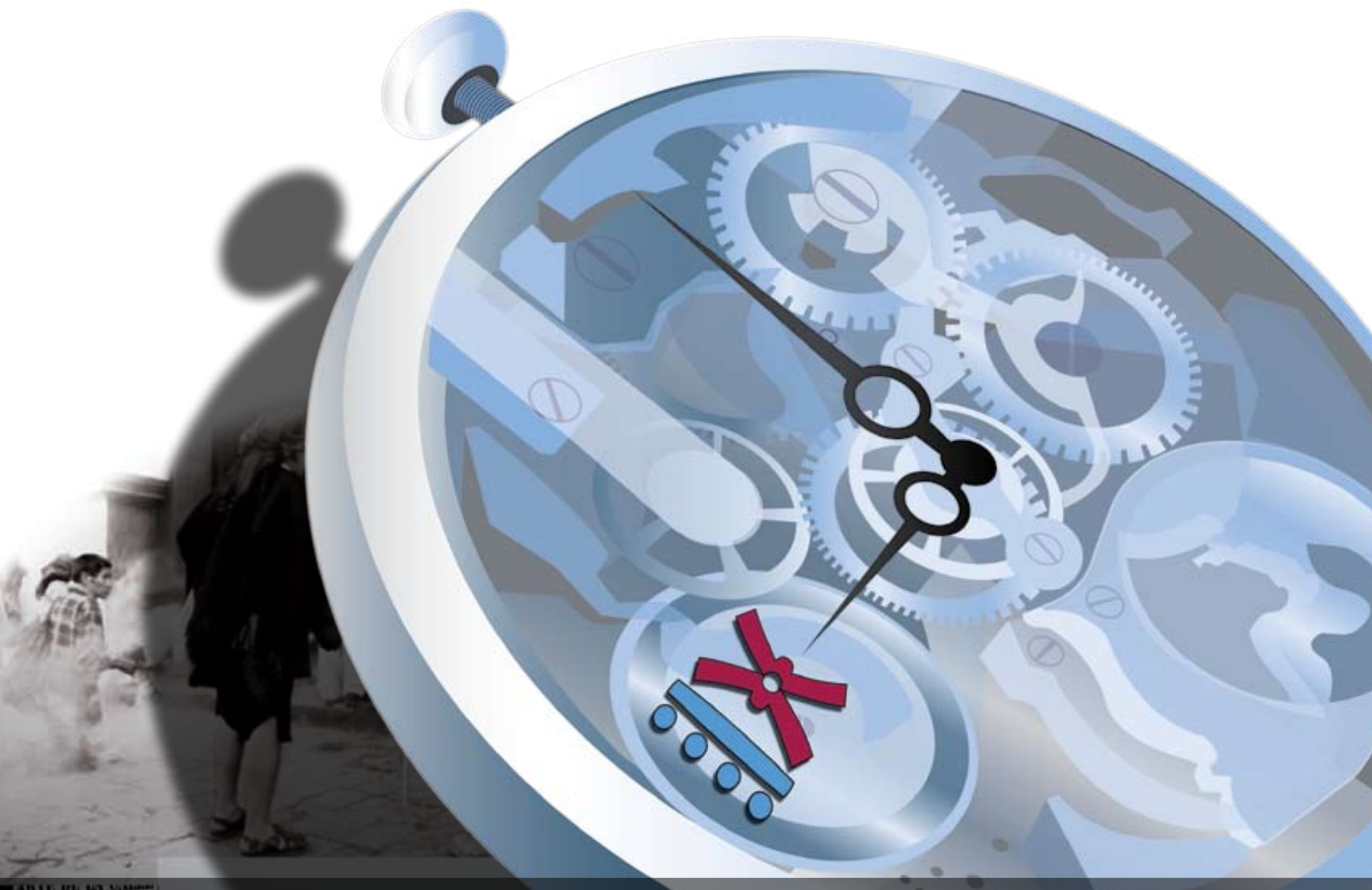

$9^{\circ}$ C O N G R E S O 2. CENTROAMERICANO DE H ISTO R I A

Universidad de Costa Rica

ISSN 1409- 469X

Fecha de recepción: 15 de mayo 2008 Fecha de aceptación: 30 de mayo 2008

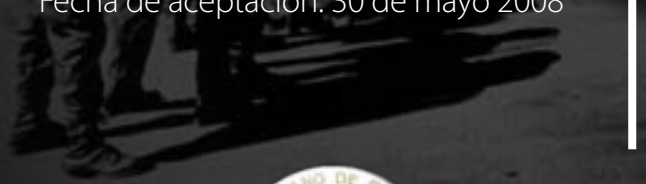

CORRE SANGRE CHIRICANA POR LAS VENAS DEL SUR ELEMENTOS PARA INTERPRETAR LA CONSTRUCCIÓN DE UNA REGIÓN. El Caso de Potrero Grande.

Miembros del Consejo Editorial:

Dr. Ronny Viales, Dr. Juan José Marín

Editores Técnicos:

Allan Fonseca, Andrés Cruz, Gabriela Soto
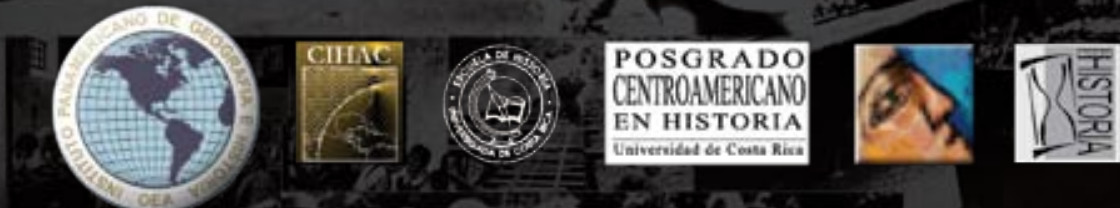
Indexaciones: Repositorio de Revistas UCR, DIALNET, Latindex, REDALYC Directorio y recolector de recursos digitales del Ministerio de Cultura de España, Directory of Open Access Journals. Diálogos Revista Electrónica de Historia ISSN 1409- 469X. Número especial 2008. Dirección web: http://historia.fcs.ucr.ac.cr/dialogos.htm

\title{
Corre sangre chiricana por las venas del sur elementos para interpretar la construcción de una región El Caso de Potrero Grande.
}

\author{
José Luis Amador
}

Instituto Costarricense de Electricidad (ICE). Programa de Indagación y Divulgación Cultural Proyecto Hidroeléctrico El Diquís. jamador@ice.go.cr. 


\title{
¡CORRE SANGRE CHIRICANA POR LAS VENAS DEL SUR!
}

\author{
Elementos para comprender la construcción de una región. \\ El Caso de Potrero Grande.
}

A doña Luz Alba Chacón, historiadora bonaerense, y a su abuela chiricana de larga cabellera.

$\mathrm{Al}$ sur y a sus gentes de tantos colores.

\section{Los chiricanos en la configuración social del sur de Costa Rica.}

A la llegada de los meseteños ${ }^{1}$, el Pacífico Sur de Costa Rica contaba ya con una significativa, aunque dispersa, población de chiricanos. A inicios del siglo XX, la afluencia chiricana, lejos de disminuir, aumenta, y su presencia se hace sentir por la formación de pequeños núcleos poblacionales, especialmente en el cantón de Buenos Aires. Por esta razón se ha dicho que "el chiricano le dio fisonomía al cantón y su presencia poblacional le dio una característica única y propia". Se ha dicho también que el indígena ya estaba allí, el chiricano llegó después, pero "la presencia del costarricense (se alude al meseteño), fue lenta y llegó de último" (ICE, 1979:63). ${ }^{2}$ Lo cierto, es que juntos, estos tres grupos étnicos, constituyen la argamasa social del sur. Paradójicamente, no se ha hecho suficiente hincapié en el significado de lo indígena y lo chiricano, en lo que respecta a la constitución de la sociedad del Pacífico Sur. En su estudio acerca de la génesis del Cantón de Buenos Aires, la historiadora bonaerense Luz Alba Chacón se refiere a la relevancia de lo chiricano, de este modo: Ha quedado manifiesto cómo el elemento chiricano dio innumerables aportes al costumbrismo bonaerense. Muchos de sus hábitos se incorporaron a la forma de ser de los nacientes pueblos de Volcán y Buenos Aires, más adelante de Potrero $G_{\text {Grande }}^{3}$ y por último de todo el cantón. Sin embargo, en su texto, el chiricano es percibido como un fuereño, que hace aportes, pero no parece formar parte integral de la sociedad bonaerense: "Los fuereños llegaban montados en briosos caballos que lucían en improvisadas carreras practicadas en la calle frente a la iglesia... Se destacaban siempre las bestias de los Gómez, Beita y Altamirano, hacendados de Volcán”(Chacón, 1986: 127). Cuando entrevistamos a doña

1 El nombre no es técnicamente correcto pero se utiliza para denominar a personas del Valle Central.

2 Nuestra investigación se focaliza en Potrero Grande y en menor medida en Buenos Aires, pero sabemos que lo mismo ocurre en otros sitios del Sur, y muy especialmente en Puerto Jiménez.

3 Contrariamente a Chacón, otros autores otorgan más relevancia a Potrero Grande, al que definen como el reducto chiricano por excelencia (ICE, 1979:54). 
Luz Alba, le preguntamos por qué en su importante investigación, el chiricano aparece como un elemento externo que dio "innumerables aportes al costumbrismo bonaerense" y no como un actor co-protagónico de la historia de Buenos Aires. Su respuesta, sonriente y apacible, como es ella, fue un reflexivo... "fijjese qué curioso, mi abuela era chiricana y mi padre nos decía a mi hermana y a mí, mis chiricanitas”. En seguida describió con cariño a su abuela: cómo reía, cómo caminaba, cómo peinaba su larga trenza, como se sentaba... y no dijo más. Posteriormente he reflexionado mucho sobre esta conversación, que fue algo así como si me dijera: lo chiricano no fue central en mi documento, pero sí estuvo en mi vida, en mi experiencia cotidiana. Creo, que lo que ocurre, es que en el momento en que doña Luz Alba Chacón, a quién aprecio profundamente, escribió su libro, la sensibilidad que teníamos con respecto a las otredades, era distinta de la que tenemos ahora. No es sino hasta hace poco, que los costarricenses nos hemos desmarcado de la subjetividad meseteña y no es sino hasta ahora, que empezamos a visibilizar a esos actores sociales "no meseteños", que también fueron constructores co-protagónicos de las regiones y de la sociedad nacional. Estaban ahí pero no los veíamos. Eran parte de nuestra carne, nuestra sangre y nuestra cultura en un sentido amplio, nacional y multiétnico, pero no teníamos clara conciencia de ello. Ahora sabemos que, al igual que ocurre a doña Luz Alba, por las venas del sur corre sangre chiricana, sin que nos diéramos cuenta, y quizá, el mayor aporte de este modesto estudio sea llamar la atención al respecto. Vale la pena entonces reiterarlo con fuerza y entusiasmo:

\section{¡Corre sangre chiricana por las venas del Sur!}




\section{Razón de ser de esta investigación.}

Potrero Grande es una comunidad de poco más de 500 habitantes que se ubica unos $10 \mathrm{Km}$. al noreste de la carretera Interamericana, entrando por Paso Real. Es el Distrito Tercero del cantón de Buenos Aires, Provincia de Puntarenas, Costa Rica. Ver figura 1. A finales del 2002, la Asociación de Desarrollo de Potrero Grande solicitó a funcionarios del Proyecto Hidroeléctrico Boruca, elaborar una historia de su comunidad. Se argumentaron dos motivos: rescatar el ancestro chiricano de los primeros pobladores y heredar a hijos y nietos el recuerdo de Potrero Grande, en caso de que esta comunidad fuera reubicada ante la eventual construcción del ese Proyecto. Posteriormente el P. H. Boruca experimentó un replanteamiento de su esquema original. En su nueva versión, el proyecto se convirtió en el P. H. El Diquís y se ubicó en el río General, de tal manera que la comunidad de Potrero Grande ya no sería reubicada. No obstante el ICE decidió continuar la investigación, no solo para saldar su compromiso con la comunidad, sino también como una contribución al conocimiento de la historia y la cultura de la región. No cabe duda que ahondar en el conocimiento de la gente y la cultura chiricana, es una manera de contribuir al fortalecimiento de la cultura del sur y la cultura del país en general. De ahí la importancia de este esfuerzo investigativo que nos lleva a conocer la historia del pequeño pueblo de Potrero Grande y desde allí echar luz sobre la presencia de los chiricanos en la construcción de sur de Costa Rica. El área de influencia de este proyecto hidroeléctrico, es una de las regiones de mayor riqueza cultural del país. Su población está caracterizada por la presencia de varias comunidades indígenas pertenecientes a las etnias térraba, boruca, bribrí, y cabécar, así como también por grupos no indígenas provenientes del Valle Central y otros de origen chiricano panameño. Al sureste, fuera ya del área de influencia, radican indígenas de la etnia guaymí. Con aportes como este, el Instituto Costarricense de Electricidad (ICE) rinde homenaje a la diversidad cultural de la región y procura contribuir a consolidar los valores culturales autóctonos de sus habitantes.

Cómo se hizo esta investigación. En esta investigación hemos utilizado el método que se denomina "historia oral". Este método consiste en reconstruir la historia de un pueblo, a partir de las narraciones de la gente. Se realizaron cerca de cuarenta entrevistas a profundidad, en su mayoría "historias de vida". En un inicio se entrevistaron personas mayores de Potrero Grande, las Vueltas y Los Ángeles, para reconstruir las etapas de llegada de los chiricanos, ingreso de los meseteños y formas tradicionales de vida de los abuelos potrereños en general. Posteriormente se hizo una segunda campaña de entrevistas destinada a conocer la forma de realizar los trabajos y 
las fiestas en Potrero Grande. Más adelante, en un tercer momento se entrevistaron comerciantes, productores y otros actores económicos para visualizar mejor la historia de Potrero Grande hasta el día de hoy. También fue de mucha importancia recurrir a testigos del proceso, como maestros, un ex - sacerdote, funcionarios, empleados de ministerios o del Consejo Nacional de Producción, quienes ejercieron como observadores y actores en determinados trechos de la historia. Todas estas entrevistas se grabaron, se trascribieron y se analizaron en un laborioso proceso. Complementariamente se llevó a cabo una indagación bibliográfica sobre historia del sur de Costa Rica e historia del Occidente Panameño, para comprender las causas que motivaron la migración de los chiricanos a Costa Rica. Se realizaron dos talleres con la participación de personas de la comunidad, uno para ubicar colectivamente hitos históricos y otro para exponer resultados y recibir retroalimentación de miembros de la comunidad. Finalmente se realizó una campaña de recolección de fotografías antiguas para ilustrar el texto. Se realizó además una recopilación de fotografías. Durante todo el tiempo esta investigación ha contado con el apoyo entusiasta de vecinos de Potrero Grande como Pastor Pinzón ${ }^{4}$, Catalina Torres, Mario Beita y cerca de cuarenta personas que contribuyeron con su tiempo, información y material gráfico.

Contenidos del libro. El producto de la investigación se sometió a consideración del Consejo Editorial de la UNED quien decidió su publicación bajo el título Historia y tradición en Potrero Grande. Un pueblo costarricense de origen chiricano panameño. El Capítulo I alude a las migraciones chiricanas, las rutas de ingreso y las posibles causas de migración al sur de Costa Rica. Hace además un recuento de los primeros pobladores de Potrero Grande. El Capítulo II se refiere a la cultura de los chiricanos. Su génesis en el occidente agrícola y ganadero panameño y su cotidianidad en Potrero Grande: los ranchos de palma, fogón, trastos artesanales, confección de muebles y camas, elaboración del jabón, aceite de gunzo, alimentación, etc. El Capítulo III, aborda los trabajos y el entretenimiento. Por una parte el cultivo del arroz, los trabajos colectivos, viajes por el río Térraba, cacería y pesca. Por otra parte las fiestas, los bailes con música de acordeón, peleas de gallos, carreras de caballos etc. El capitulo IV, más orientado hacia la evolución económica, hace una revisión de la historia de Potrero Grande desde 1900 hasta la actualidad.

Importancia de la cultura chiricana en el Sur. Potrero Grande es un pueblo fundado por

$4 \quad$ El caso de Pastor Pinzón es especial porque su interés lo llevó a iniciar artesanalmente esta investigación por su cuenta. Posteriormente nos acompañó en todo el proceso convirtiéndose en compañero y apoyo moral de la indagación. 
chiricanos, donde hoy conviven hijos y nietos de chiricanos, con gente de ancestro indígena y gente del Valle Central, porque así es el sur de nuestro país, mezcla de sangres y culturas. La población del sur de Costa Rica se formó a partir de esas tres grandes vertientes: indígena, meseteña (Valle Central) y chiricana. De modo que la cultura de los chiricanos es uno de los tres sustratos culturales esenciales de esa región. Sin embargo, no existe en Costa Rica un solo libro que hable expresamente de los chiricanos, como tampoco conocemos historiador alguno que se haya detenido específicamente a contar la historia de su llegada y a dimensionar su aporte. Pero ocurre que en el sur todo el mundo sabe que ellos son parte de su historia. ${ }^{5}$ Los chiricanos son a su vez, el resultado de la mezcla de poblaciones indígenas del occidente panameño, con gente hispánica y negra. Su arribo a la poco poblada zona sur de Costa Rica a finales del siglo XIX y principios del XX, parece haber sido causada por factores diversos, fundamentalmente guerras, conflictos políticos y falta de tierras para cultivo y pastoreo. A su ingreso al territorio que hoy llamamos Costa Rica, los chiricanos todavía eran portadores de muchos elementos culturales indígenas, como la elaboración de chicha, ranchos, hamacas, utensilios de jícaro, mezclados con otros rasgos de claro origen hispánico, como la monta de caballos, el uso de coplas y décimas, lengua y religión. Su llegada se produce por acción espontánea de familias dispersas. En algunos lugares del sur de Costa Rica, los chiricanos llegaron a tener una presencia significativa, tal es el caso de Potrero Grande, Volcán, Pilas y Puerto Jiménez, pero su huella está en todo el Sur. Con el paso del tiempo esta población chiricana se fusionó con la de los tico-meseteños, debido en parte a la evolución histórica de la región, pero también, afirman algunos, a la gran adaptabilidad de la cultura chiricana.

Los chiricanos ya estaban allí. En 1861 el Gobierno de la República de Costa Rica ofreció una recompensa a quien encontrara un camino de Cartago a Térraba y Boruca. No fue sino hasta 1868, cuando Pedro Calderón y su yerno, acudieron a reclamar su premio de cinco mil pesos por haber encontrado el camino. Con la apertura de la "picada Calderón" dio inicio la colonización de la región sur de nuestro país. Un año más tarde, en 1869, el propio Pedro Calderón fundó el pueblo de Buenos Aires, primer poblado "tico" en el sur... Solo que, cuando los ticos se establecen en

$5 \quad$ El tema de los chiricanos en Costa Rica ha sido abordado por la historiadora Luz Alba Chacón en su historia de Buenos Aires (1986) y retomado posteriormente por Bozzoli y Wing Ching (1979), por los estudios del ICE (Informe Anual de labores 1979 y 1980) y por Carmack (1994). En todos los casos se les menciona dentro del contexto de la historia del cantón de Buenos Aires y del sur de Costa Rica. Sin embargo no ha habido un estudio que se ocupe del tema de manera específica. 
el Sur, los chiricanos ya estaban allí. ${ }^{6}$ En 1845 había chiricanos en el Golfo Dulce. Documentos de la época se refieren a la "afluencia de chiricanos" y expresan la preocupación del gobierno, porque ya en 1836 Colombia había despojado a Costa Rica del territorio de Bocas del Toro. En 1848 un chiricano nacionalizado costarricense, se estableció en Golfo Dulce junto con 88 chiricanos más, fundando el caserío de Puntarenitas, origen del actual Puerto Jiménez. Para 1850, vecinos del distrito de Santiago de Alanje (Chiriquí) llevaban ganado a pastar hasta la margen izquierda del río Coto e incluso consideraban al litoral entre punta Burica y el río Esquinas, como propio de Nueva Granada (García, 1988: 33). En 1871, José Ma. Figueroa durante un recorrido exploratorio por la zona sur, encontró chiricanos en Hato Viejo (actual Buenos Aires), llanos de San Andrés, boca del río Barú, Boca de Hatillo Nuevo y en otros sitios. Más tarde, a finales del siglo XIX, chiricanos, costarricenses, jamaiquinos y nicaragüenses habitan en el Pozo, hoy ciudad Cortés. A inicios del siglo XX, había chiricanos en Pilas, Volcán y Potrero Grande. Para 1920 se habla de chiricanos en el Tigre, Sándalo, La Aguja, Playa Blanca, Rincón, La Palma, San José, Ojo de Agua y Golfito. (Obviamente estaban desde más antes). Al parecer no eran grandes grupos, sino más bien familias dispersas, en un proceso de colonización lento, debido a la falta de vías de comunicación (García, 1988: 33).

Rutas de ingreso: Se mencionan tres rutas de ingreso de los chiricanos en su arribo a la región sur de Costa Rica. Primera: es la ruta de Cañas Gordas. Comunica con Paso Real y sirvió para la colonización de Las Vueltas, Sabalito, Cañas, Potrero Grande, Térraba, Buenos Aires y Volcán. Segunda: es la Ruta de la Cuesta. Unía David, Divalá, Concepción y Alanje, con Puerto Nuevo y Golfito y el actual Puerto Jiménez, (...) la vía natural fue el río Coto. Tercera: Una tercera vía fue la marítima; contribuyó a colonizar Punta Burica, cabo Drake y el litoral Pacífico. El proceso colonizador de los chiricanos ocurrió en la segunda mitad del siglo XIX y terminó con la delimitación de la frontera en 1941 (ICE, 1979: 53) Ver figura 2.

\section{Potrero Grande: Un pueblo de chiricanos}

\section{Los que hicieron a Potrero Grande fueron chiricanos,}

$6 \quad$ También los boruca, durante siglos habían ocupado aquellas tierras y los térraba o teribes habían sido traídos hacia 1700 por los frailes españoles, desde la Región Atlántica (Guevara y Chacón, 1992: 111). 
no le están mintiendo ¡panameños!

Agustina Caballero.

Potrero Grande es un pueblito pequeño. Tan solo un puñado de casas, no más... pero sus calles están llenas de historias y recuerdos. Nadie sabe a ciencia cierta en qué momento el abuelo dijo un día: nos vamos para aquel otro lado. Entramos por Cañas Gordas y nos vamos allá por el lado de Costa Rica, por donde llaman Potrero Grande. - Y así lo hicieron, siguiendo el camino que ya habían andado los otros. - Dicen que ahí hay tierra, por ese lado. ¿No ves que ya antes se fueron los Palacios, los Torres, los Ibarra, los Cedeño, los Valdez, los Saldaña y todos los demás? Y fue así como se fue poblando Potrero Grande, un pueblo de chiricanos. Es por eso que cuando en Potrero Grande los mayores echan a andar su memoria y nos hablan del pueblito que conocieron en su infancia, en la época de sus abuelos, lo primero que hacen es recordarnos que aquella era una comunidad de panameños. Bernabela Pití Morales, 93 años, con su risa y su voz apenas audible, lo testimonia así: Cuando era pequeña, aquí, la mayoría eran panameños. Conocí una hacienda de ganado aquí, que era de panameños y después mucha gente aquí, eran panameños. Uno que se llamaba Santana Valdez, esa gente eran los primeros que yo conocí. De ese señor conocí la mamá que se llamaba ña Ginia Valdezy la hermana se llamaba Juliana. Toda esa gente era panameña.

Lo cierto es que en los albores del siglo XX, este apartado rincón de la geografía nacional se convertiría en uno de los sitios de mayor población de chiricanos en Costa Rica. Tal y como se ha escrito: "Potrero Grande fue por excelencia el reducto chiricano y en menor grado Volcán" (ICE, 1979:54). Consultado al respecto don Cristino Lázaro, indígena de la comunidad de Curré, que durante la primera mitad del siglo XX mantenía algún contacto con los potrereños, nos cuenta: Potrero era el centro de los chiricanos, - y agrega - antes no se hablaba de Panamá, sólo de

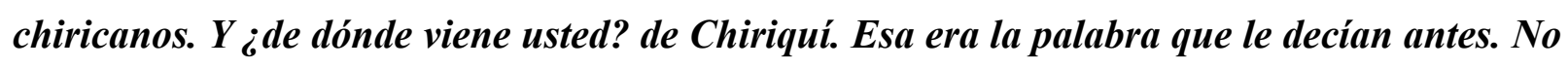
le decían Panamá, sino que le decían Chiriquí. Cabe entonces preguntarse ¿Por qué vinieron los chiricanos a Potrero Grande? 


\title{
Causas de la migración chiricana a Costa Rica
}

\begin{abstract}
“Talvez allá no tenían un pedacito de tierra, entonces vinieron buscando adónde hacer una vida. Las tierras eran libres. Venía un panameño, hacía un carril en una montaña y se ponía a trabajar. Nadie le decía no trabaje”.
\end{abstract}

Claudio Beita Morales.

Las causas de la migración de chiricanos hacia el sur de Costa Rica fueron diversas. Algunas se debieron a procesos internos que venía experimentando la sociedad chiricana y otras a características propias de la región sur de nuestro país. Al analizar cada aspecto se hará uso de fuentes bibliográficas y luego de fuentes orales (Ver Fig. 3).

* Falta de tierras. Una de las posibles causas de migración hacia el sur de Costa Rica, fue la pérdida de tierras por parte de sectores campesinos chiricanos de origen indígena. A mediados y finales del siglo XIX, buena parte de las comunidades indígenas del sector chiricano ya habían sido desestructuradas, los indígenas hispanizados y convertidos en campesinos o peones de hacienda, y en muchos casos despojados de sus tierras. El historiador panameño Alberto Osorio Osorio se refiere a este proceso usando los términos "hispanización" y "desplazamiento" y da como ejemplo lo ocurrido en San Miguel de Boquerón y la Purísima Concepción de Bugaba cuando el campesinado ocupa las antiguas posesiones indígenas (Osorio, 1988: 291 -292).

También los testimonios orales de los potrereños aluden a la falta de tierras como causa de la migración chiricana hacia Costa Rica. Con su voz apagada por los años, Pedro Guerra, un chiricano de Potrero Grande que actualmente vive en Curré, comenta: Allá todo estaba ajeno, la tierra... Y acá venían y veían que había libertad... La expresión "allá todo estaba ajeno", pone en evidencia una de las razones más importantes para migrar a Costa Rica: el acaparamiento de tierras en el sector chiricano, la expulsión de campesinos y la existencia de vastas extensiones de tierra libre en el sur de Costa Rica. Porque como dice Pastor Pinzón, se les fueron llenando la mente y los ojos de inmensidad, y comprendieron que aquella sería una buena tierra para ellos y sus hijos: Había más posibilidades de obtener independencia y tierra aquí. Los que ya han venido antes, manifestaban a los otros la extensidad de terreno para trabajar. Entonces a ellos se les llenó la mente y los ojos... Decían: hay que ir ahí, a abarcar terreno para la familia. Unos llamaban a los otros. Los desposeídos, los que no tenían "posición" directa (sic), es decir, los que carecían de propiedad, se fueron viniendo y como les iba bien, llamaban a sus 
familiares. Al menos así lo entiende Pastor Pinzón: Ahí se vinieron porque unos descubrieron el lugar y los demás se iban viniendo. Ese chiricano que llega al sur de Costa Rica, nos parece, era un indígena de reciente hispanización, como lo sugiere entre otras cosas su cultura material: el rancho, utensilios de jícaro y cerámica, cobijas de mastate, etc. A ello se suma la facilidad con la que los recién llegados se enlazan con mujeres indígenas, especialmente de origen térraba.

* Expansionismo ganadero y agotamiento de tierras. Asegura Jaén que el sector dominante panameño, prestó más importancia al ganado que a la agricultura. La tenencia de ganado se convirtió en signo de prestigio y "la magnitud del hato señala un elemento de status" (Jaén, 1979: 190). El agotamiento de pastizales se resolvió con más deforestación e incremento de tierras ganaderas, pero también con disminución de la densidad del ganado (Jaén, 1979: 197). La presión de los ganaderos sobre las tierras fue entonces otro factor más, que explica la necesidad de encontrar nuevas tierras para la agricultura, pero también nuevas zonas boscosas para la cacería y la producción artesanal, acordes con la cultura y el modo de vida autosuficiente de amplios sectores chiricanos, como los que llegaron a Potrero Grande.

* Rotación del ganado. En su estudio sobre población y economía en Panamá, Omar Jaén explica que uno de los mecanismos utilizados en Chiriquí para solucionar el agotamiento de pastos fue la rotación anual del ganado entre "las planicies aluviales y los llanos secos". Según este autor, del mes de octubre al mes de enero las sabanas naturales, servían para alivianar la presión que soportaban las planicies aluviales durante el resto del año, dando tiempo al crecimiento de nueva vegetación antes del regreso del ganado (Jaén, 1979: 203). En efecto, los testimonios de los potrereños hablan de una poderosa familia ganadera, los Guerra, que a principios del siglo XX, ingresaba anualmente hasta Potrero Grande, arreando ganado, el que tras su engorde, retornaba a Chiriquí para su venta. Doña Martina Bonilla describe así el ciclo de entrada y salida del ganado: Aquí había una gente de familia Guerra de Panamá, que a principios de invierno metían aquí ganado para engordar y lo volvían a sacar en verano. Entonces le pusieron Potrero Grande, por eso. Estos eran pastos naturales, pero grandísimos. El ganado lo traían a engordar en invierno y lo sacaban cuando ya iba a entrar el verano. Y se lo llevaban otra vez para Panamá. Seguro eran crías de ganado que ellos hacían, grandes, de una familia Guerra de Panamá, de Chiriquí. Y pasaban por la montaña, aquí, por Cañas Gordas. Martina Bonilla. Los testimonios dan cuenta de que algunos peones chiricanos de los Guerra terminaron casándose y afincándose 
en la región de Potrero Grande (Ver Figura 4).

* Un clima de constantes guerras. Otros chiricanos ingresaron a Costa Rica huyendo del clima permanente de guerras, inseguridad y zozobra política que azotó al Istmo Panameño y a la provincia de Chiriquí en particular, durante buena parte del siglo XIX e inicios del XX, dando origen así a sucesivas migraciones hacia el sur de Costa Rica. Este clima bélico nos queda claro con la ayuda de historiadores panameños, como Ernesto Castillero: "Después de la independencia de España en 1821, Panamá se unió a Colombia haciéndose parte de la Confederación de Nueva Granada. Esta Confederación experimentó fuertes convulsiones políticas que la llevaron a un estado de guerras intermitentes. Ya desde 1861 un grupo de chiricanos "reunidos pacíficamente y sin armas" expresa su preocupación por las "luchas fratricidas" que permanentemente vive la federación granadina... Se quejan de "la frecuencia con que los partidos políticos apelan a las armas" (...) tal parece que "una revolución prepara otra revolución". Manifiestan que los istmeños son víctima de "reclutamientos, contribuciones extraordinarias, abolición y cercenamiento de las garantías individuales, desconfianza en el interior, descrédito en el exterior, desmoralización, miseria" (Acta de Chiriquí, Castillero, 1968: 48). Pero las guerras no siempre vinieron de fuera, sino que también en Chiriquí se promovieron varios movimientos bélicos. En 1860, el levantamiento de Obaldía. En 1868 dos levantamientos. En 1871, la revolución encabezada por Tomás Herrera. En 1873, un nuevo movimiento armado contra el General Gabriel Neira y en 1884 chiricanos se involucraron en la sublevación del Gral. Benjamín Ruiz... "La más trascendental de las revoluciones, fue la que estalló en marzo de 1900, cuando una fuerza invasora de 110 hombres, organizada en Centroamérica, (...) inició la más desastrosa guerra civil que azotó el Istmo, invadiendo la Provincia de Chiriquí por Punta Burica..." (Castillero, 1968: 90 - 92). Este clima de inestabilidad favoreció las migraciones.

La tradición oral es fiel reflejo de esta situación. No es extraño que algunos potrereños mencionen que sus padres y abuelos migraron a estas tierras huyendo de las guerras, las persecuciones políticas y el reclutamiento forzoso en diversos conflictos bélicos, o bien por temor a venganzas y represalias. Pastor Pinzón narra el caso de Evaristo Arauz: Sus padres venían de Exquisito, de Chiriquí, un lugar que está antes de llegar a Concepción. El motivo de venirse era huyéndole a la guerra de Colombia con Panamá, que todavía no se habían independizado, pero estaban dentro del proceso de la revolución. (...) Entonces lo que hacían los padres era pasarse a este 
lado tico. Escuchemos el relato de Maximiliano Morales, gran conversador y tocador de acordeón, a quien recordamos con aprecio, aunque lamentablemente falleció recientemente: Amigo, tengo 99 y medio años... Los primeros chiricanos Ilegaban a las Vueltas. Luego pasaban por Buenos Aires y seguían por allá, por el General Viejo, que llaman. Prácticamente no había ticos por esa época. No, no había, solo los indios Térraba y Boruca. En Buenos Aires no había ticos, todos (los chiricanos) venían de allá, por la ruta de San Vito. Muchos pasaron para allá y se volvieron para atrás, (a Chiriqui) otros se quedaron. Es porque esta Revolución de Panamá, empezó por ahí de 1899 y terminó en 1903. Mi papá me contaba, después yo leí algo. Maximiliano Morales.

Otras causas del lado de Costa Rica: La migración chiricana se vio favorecida por características propias de la región sur de Costa Rica, a saber: marginalidad, escaso desarrollo, tierra disponible, poca población, aislamiento, reducida presencia estatal y una frontera común prácticamente indefinida desde épocas coloniales hasta bien entrado el siglo XX. En la región de Chiriquí, las poblaciones controladas por españoles se fundaron tempranamente y alcanzaron más prosperidad que en el sur de Costa Rica. Ni los españoles durante la colonia, ni el gobierno de la República de Costa Rica, lograron tener presencia significativa en el sur del país sino hasta finales del siglo XIX. La primera vía terrestre fue la picada Calderón construida en 1868, y el primer pueblo no indígena fue Buenos Aires (1869). Según los testimonios, en Potrero Grande el Estado costarricense adquiere presencia lentamente, mediante la acción de funcionarios como el policía, el cartero o el maestro, y se puede afirmar con García (1988) que "por lo menos hasta la década de 1930 la mayor parte de la Zona Sur (...) permaneció al margen del desarrollo económico del país”. De manera que, la región sur de Costa Rica, con extensos territorios, poco poblada y escasamente accesible para el Estado y para los costarricenses de la meseta, fue hasta bien entrado el siglo XX, un espacio idóneo para los chiricanos, quienes deseosos de tierra y de estabilidad social, cruzaban una frontera prácticamente inexistente. Esto da como resultado además una suerte de marginalidad y aislamiento. Potrero Grande era un espacio inaccesible, un sitio ideal para esconderse, una especie de isla encerrada entre ríos, donde venían a parar forajidos y profanadores de tesoros arqueológicos. "Aquí era un refugio de los que eran fugitivos de la 
ley del lado de Panamá”. (Agustín Avilés). ${ }^{7}$

Tierra preñada de nombres chiricanos. Y fue así como aquellos campesinos chiricanos comenzaron a emigrar, y no se conformaron con llegar a Potrero Grande, sino que algunos fueron mucho más allá, territorio adentro. En palabras de Mario Beita, los panameños iban llegando casi a Pérez Zeledón, de Volcán para allá... Y asegura Vicente Guerra que "no sólo aquí en Potrero Grande, usted puede ir a Volcán; eso ya era panameños, toditos, San Isidro, en ese tiempo... Ahora no, pero en ese tiempo la gente era Beita y el apellido Beita es panameño. En Dominical, un señor de Gualaca también, llamado José Quirós Pití, allá donde se llama La Uvita. En Puerto Jiménez, un señor de apellido Serrú, y así...” Fue así como de Cañas Gordas a Potrero Grande y más allá, el paisaje se fue llenando de nombres intensos y sonoros, apellidos como Saldaña, Lezcano, Pití, Serracín, Grajales, Pinzón, Zapata, Caballero, Palacios, Ibarra, Valdez, Cedeño, Rueda, Arauz, Reyes y otros de una larga lista. A inicios de los años treinta predominaban los chiricanos en Potrero Grande. Así lo atestiguan los primeros ticos en llegar. Martina Bonilla, hija del primer policía que llega al pueblo, recuerda: en ese tiempo era un pueblo muy bonito, por la razón de que había mucha gente campesina: los panameños. Y decía papá que aquí había mucha gente campesina, porque aquí había muchos ranchos... Todavía en 1938, René Villalobos, un alajuelense, recién llegado a Potrero, observaba: la gente en un noventa y cinco por ciento, eran panameños. (Ver figura No. 5).

\section{Primeros asentamientos.}

\section{El que toma agua del río Guineal vuelve a Potrero Grande.}

Recopilado por Barboza y Montero (2002)

No fue el centro de Potrero Grande, el primer lugar en ser habitado, sino más bien los sitios aledaños, denominados Guadalupe y Buril, al parecer con más fuentes de agua que el

$7 \quad$ Estos temas son tratados con más detalle en el libro citado, publicado por Editorial UNED. Ver también el artículo "Chiricanos en Costa Rica", publicado en Sánchez Pereira, Maureen et al, Arqueología del Pacífico Sur de Costa Rica: Nuevos aportes y reflexiones. Editorial UCR. Actualmente en prensa. 
centro. Las orillas de los ríos Platanillal, el Guineal y otros riachuelos como el Potrero, también fueron ocupadas (Agustina Caballero, René Villalobos). Es comprensible entonces que fuera en Buril, donde por muchos años estuviera el cementerio. Y es allá adonde están enterrados los restos de los primeros chiricanos fundadores de Potrero Grande. Asegura doña Martina, que todavía en 1933, una hermana suya fue enterrada en ese cementerio, a pesar de que ya vivían en Potrero Grande. De igual modo, la memoria de los potrereños, recuerda la existencia de una iglesia que sus antecesores construyeron en Guadalupe, con teja traída desde Chiriquí. El pueblo de Guadalupe tampoco existe actualmente y solo quedan vestigios de lo que fue una población. Mientras tanto, el centro de Potrero Grande, era por aquel entonces una sabana de altos y tupidos pastizales. Fue allí, casualmente, donde los hermanos Guerra asentaron sus hatos de ganado.

Los hermanos Guerra. El nombre de los hermanos Guerra, de Concepción, Chiriquí, es frecuentemente mencionado entre los primeros en llegar a Potrero Grande. Su ingreso se ubica en los alrededores del año 1900. A veces se les llama "Guerra Hermanos", lo que podría ser indicio de tratarse de una empresa familiar. Su propósito al entrar a esta región, fue el pastoreo de ganado en cantidades relativamente grandes. Se menciona con insistencia la cifra de cuatrocientas a quinientas. Son los hermanos Guerra los primeros que se asientan con su hato en las sabanas del centro de Potrero Grande. Los Guerra cogieron eso hasta allá, a Boca de Limón, llegando a Brujo. Entonces soltaron unas quinientas reses. Esto era puro potrero, uno a caballo no se veía, unos potreros de sabana, que las vacas los comen bien. Este ganado lo traían y se lo volvían a llevar para venderlo en Panamá. Se traía delgado y nuevo, (joven). Se desarrollaba aquí y se llevaba allá. Ellos lo hacían anualmente (Agustín Avilés). Se dice que los Guerra no fueron colonos, sino más bien hacendados no residentes, ausentistas, que especulaban con el ganado y contrataban sabaneros para realizar el trabajo. Entre sus sabaneros se citan los nombres de Juan Concepción e Hilario Rueda, quienes sí llegaron a establecer familias en Potrero Grande. Con respecto a los Guerra, algunos datos se repiten tanto, que parecen mezcla de mito y verdad. Se dice que el ganado era dejado a su suerte y llegaba a encontrarse en estado semisalvaje. A veces las reses eran víctima del tigre, que asolaba solapado entre los altos pastizales, otras veces se dice que al ganado silvestre le crecían altas ramazones en vez de cuernos. Don Agustín Avilés cuenta que... en aquel tiempo echaban el ganado en un potrero y lo dejaban ahí. Nadie curaba, nadie hacía nada. Se dice que, yo no lo he visto, pero se dice que cuando vinieron a 
ver el ganado, hasta comején tenía en los cachos, ramazones altísimas y eran otra clase de animales. Esos animales eran tan chúcaros, - asegura Maximiliano Morales- tan chúcaros, tan silvestre, que adonde había gente las chollaban, las espantaban entonces...

Los Guerra salen de Potrero Grande. Cuenta la tradición oral que durante el episodio histórico de la revuelta contra los Tinoco (año 1919), soldados de uno de los bandos involucrados en el conflicto, mataron y comieron reses de los Guerra, quienes se enteraron al ser avisados por los sabaneros. El dato permite apreciar la larga permanencia de los Guerra en la región, periodo que alcanza unos veinte años. Este evento es la última referencia que se hace de los Guerra. No parece que su presencia se haya prolongado mucho más. Póngame cuidado, los hermanos Guerra tuvieron que sacar el ganado, porque se lo estaban comiendo los mismos revolucionarios. (...) Un cuidador tuvo que salir de aquí y comunicar a los hermanos Guerra, lo que estaba sucediendo. En Panamá ya sabían el problema (político). Lo que menos sabían los hermanos Guerra, es que les estaban robando el ganado (Pastor Pinzón). Se asegura que algunos lugareños, quizá de Buril, también sacrificaron y consumieron de este ganado. Don Maximiliano, sostiene que la salida de los Guerra permitió la entrada definitiva de los potrereños al centro de Potrero Grande. Critica el hecho de que los potrereños se comportaron siempre como si este sitio perteneciera a los Guerra, cuando no era así. Y asegura que esto ocurría porque aquellos campesinos, eran gente "sencilla e ignorante". Con la salida de los Guerra se inicia el paulatino poblamiento del centro de Potrero Grande.

Los primeros pobladores. Un recuento familia por familia. Nacida en 1914, fue Leonor Lezcano Valdez, quien con su prodigiosa memoria nos ayudó a reconstruir el orden de llegada de los colonos. Reitera doña Leonor que los primeros en llegar a Potrero Grande -- y si no al menos los más célebres -- fueron los hermanos Guerra: Daniel, Lucinio, Asunción y Abigail. Posteriormente menciona las familias Concepción, Villarreal y Serracín, seguidas muy de cerca por los Morales, Valdez y Beita. No hay certeza respecto al orden exacto, pero todo hace suponer que todos habían ingresado ya en la primera década del siglo XX. En el documento original se hace un recuento de cada familia. 


\section{La cultura chiricana.}

Cuando los chiricanos llegaron a Potrero Grande empezaron a poner en práctica su forma de vivir la vida, es decir, su cultura. Hacer sus ranchos de palma, fabricar sus trastos de jícaro, elaborar su vajilla de barro, tallar sus muebles de madera, cocinar su totorrón y su "bienmesabe", producir su jabón de gunzo, sembrar su frijol de palo, criar sus gallos de pelea, disfrutar su música de acordeón y echar versos y salomas. Es de suponer que aquellos que cruzaron la frontera no manejaran toda la riqueza cultural de la provincia de Chiriquí, porque el emigrante a menudo es marginal, o bien, tiene su versión particular de la cultura, sin embargo, es hacia allá, hacia Chiriquí, hacia donde hay que volver la mirada, si es que queremos comprender de dónde provino su bagaje cultural. Conviene tener presente que los chiricanos vienen de la parte agrícola y ganadera de Panamá, que se extiende al occidente, hacia la frontera con Costa Rica, abarcando la región de Chiriquí. Es en este espacio donde se forjó el chiricano (Osorio, 1988: 56). Allí donde según se dice, "los naturales llamaban la alta cumbre con el nombre "Cheriqué" o "Cheriquí", que significa Valle de la Luna..." (Castillero, 1968).

La región de Chiriquí estuvo originalmente habitada por pueblos indígenas, entre ellos los dolega, bugaba, doraces, caribó y buricas. A partir de 1589, los españoles empezaron a fundar poblados bajo su dominio. Surgieron entonces Nuestra Señora de los Remedios (1589) Santiago del Ángel, actual Alanje (1591), David (1602), San Félix del Guaymí (1606), Nuestra Señora del Prado de Tolé (1621), San Lorenzo del Guaymí (1623), San Francisco de Dolega (1637), Nuestra Señora de los Ángeles de Gualaca (1766), San Miguel de Boquerón (1767), Concepción de Bugaba (1794). Estos pueblos se convertirían en despensa y fuente de productos de abastecimiento para Panamá. ${ }^{8}$ Una de sus principales características fue su diversidad étnica y cultural. ...Eran gente de color, mulatos, zambos, indios y blancos, sumamente dispersos en la campiña y poco apegados a los preceptos religiosos. Al menos así diría el obispo Morcillo a su paso por Chiriquí, en 1736 (Osorio, 1988). Asegura Osorio que a mediados del siglo XIX, en la sociedad chiricana predominaba ya el mestizo (Osorio, 1988: 800). Eso explica entonces por qué los hombres y mujeres que a principios del siglo XX llegaron a Potrero Grande provenientes de Chiriquí, todavía bebían chicha de maíz y construían ranchos de tradición indígena, a la vez que montaban a caballo, improvisaban décimas y rezaban a la usanza española, pero también, durante las faenas $8 \quad$ Nombres y fechas según mapa fundacional de Chiriquí, elaborado por Osorio (1988:23). 
colectivas, pregonaban cantos de trabajo al modo de los africanos. Cultura mestiza, ciertamente, cultura de mezclas y mixturas, cultura chiricana. ${ }^{9}$

El modo de vida de los chiricanos radicados en Costa Rica ha sido descrito así: Los ranchos a veces no tenían paredes, aunque como los indios, utilizaban siempre un tabanco para dormir o servir de bodega. La escalera para subir al tabanco era del tipo que utilizan los indígenas, un solo tronco redondo con muescas para apoyar los pies. Hacían candelas de cera silvestre y recipiente de jícara. Jabón de corozo, comidas típicas como el guacho, el bienmesabe, el almojábanos, los tamales de arroz, los panecitos y el arroz tostado. De los chiricanos aprendieron los indios sus peculiares formas de amansar caballos, montar bueyes y utilizarlos para jalar carga. Aprendieron a hacer sombreros, rezos, juegos, licores y festividades. Otro rasgo chiricano es la afición por las galleras, y las carreras de caballos utilizando gallos con el cuerpo enterrado a los que se les arrancaba la cabeza. Gustaban cantar décimas satíricas y alegres, e introdujeron el punto y la cumbia. Varias autoras subrayan el hecho de que, con excepción de las familias chiricanas más ganaderas, esta población se integró sin dificultad con la población indígena (Bozzoli y Wing Ching, 1979; también Chacón, 1986). Destaco una vez más la cantidad de rasgos culturales comunes en ambos repertorios culturales, indígena y chiricano. El rancho y la chicha, por ejemplo. Otro aspecto en común es la realización de trabajos colectivos denominados "juntas". Finalmente, es notorio el hecho de que los boruca, en su tradicional Juego de los Diablitos, todavía hoy conservan el acordeón y el canto de salomas, cuyo origen es chiricano. Estos son rasgos "apropiados", considerados ahora parte de la cultura tradicional boruca.

Se dice que a finales del siglo XVIII, un "viajero ilustrado", dejó escrito que la mayoría de los habitantes de Chiriquí eran "incultos y sin doctrina", puesto que muy pocos sabían leer y escribir, aún tratándose de jueces o miembros del Municipio. Juan Franco, que así se llamaba este viajero, "deplora la falta de cultura de los habitantes del poblado, el alto índice de analfabetismo..." Sin embargo, admite que se sintió especialmente admirado por la destreza de los vaqueros chiricanos y su esmero para cuidar sus reses, y dejó escrito que, a tono con estas labores, se daban sus diversiones, entre las que mencionó las corridas de toros, las carreras de caballos y las competencias de lazo. Franco describió "el arte de vaquear" de los chiricanos y admiró la destreza de los vaqueros en la práctica de "una actividad que él llama antigua, ya en el siglo XVIII" (Osorio, 1988: 240). Hoy, cuando leemos el testimonio de aquel lejano viajero que pasó $9 \quad$ Es de suponer que existía diversidad cultural dentro de la misma sociedad chiricana. Sin embargo, aquellos chiricanos llegados a Potrero Grande parecen tener todavía una fuerte tradición indígena, hispanizada. 
por tierras chiricanas, caemos en la cuenta de que si bien, muchos de aquellos hombres no sabían escribir, eran en realidad poseedores de una rica cultura, fuertemente orientada hacia la ganadería, la autosuficiencia y la alegría de vivir, y que estos son rasgos todavía presentes en el modo de ser de los chiricanos. El aporte de los chiricanos a nuestra cultura costarricense y específicamente a la cultura del sur de nuestro país, es un legado de cotidianidad, de convivencia, que nos dice cómo lazar un caballo, cómo preparar un guiso, o bien, como traer alegría a la vida con un acordeón, una copla y una saloma. ¡Y qué buena cosa es todo esto para un pueblo!

\section{Las fiestas en Potrero Grande ${ }^{10}$}

(Fragmento...)

Yo tenía un caballo y me fui pa' la fiesta.

Los recuerdos de Juan Chiricano.

En aquella época la gente se divertía mucho, es que tenían el estilo panameño. Eso es que en la fiesta tienen carreras de caballos, pleitos de gallos, bailes y comedera en abundancia... Aquí en Potrero Grande las fiestas eran especiales. La Navidad, el Año Nuevo. Esos días ellos tenían fiestas en sus casas, hacían tamales y hacían comedera y todo eso... Ellos hacían comidas, hacían unas ollas de "bienmesabe" y cosas así, chicha... Los chiricanos hacían la chicha de maíz nacido. Nacían un maíz y lo molían, y después, bien cocido, lo echaban en unos cubos, que antes habían, como unos calabazones grandes. Entonces ahí la echaban. Hasta se enfuertaba si querían, no la dejaban dulce. Entonces eso se les enfuertaba. Pero además de esas fechas, aquí se celebraba el día de Santiago, el San Juan, el San Pedro y la Candelaria. Como habían panameños que eran alegres y buenos para trabajar en las fiestas. Ahora no. Ummm... la vida era bonita, muy linda... una fiesta duraba tres, cuatro días. Toda la gente de todos los pueblitos se reunía y venían todos aquí. Gente de Volcán y Boruca. Venía mucha gente de Guadalupe, de Térraba, de Buenos Aires, todos se arrimaban a esas fiestas. Gente chiricana, gente panameña. Sí, los Beita, todos esos eran panameños. De Panamá no venían, venían de las Vueltas y Jabillo, porque también eran panameños. El pueblo era unos ranchos en esa época, ranchos de hojas de palos. Todo el mundo se vestía lo mejor que pudiera. Las mujeres siempre tenían... uno siempre tenía los vestidos para la fiesta, siempre se ponía lo mejor que uno tenía para las fiestas. Algunos se calzaban, otros no.

10 Estas narraciones fueron elaboradas "enhebrando" testimonios de informantes diversos. 
Yo conocí a mucha gente que iba a las fiestas descalzos. Las muchachas sí se pintaban; para ir a una fiesta, a un baile, se adornaban. Usaban peinetas, aretes, collares y más de una cosa. Collares de perlas y habían unos brillantes, se los ponía uno y después unos vestidos que todo era perlas, por aquí, así. Bien bonitos. Los compraban en Chiriquí. Ahí sí había de esos adornos, de esos lindos, y esos collares... yo no sé cómo, que salían antes. Nosotros íbamos a Chiriquí todos los años, a pie, sí, caminando, duraban cuatro días para llegar a El Ángel (Alange).

\section{... Y bailar toda la noche, con música de acordeones.}

En esos tiempos amanecían las fiestas. Más si se trataba de fiestas patronales, con mucha más razón, que hubiera música durante toda la noche, la madrugada y al día siguiente. Eso era lo importante. Así lo relata don José Santos Concepción. Aquí, juepulla, recuerda entre risas doña Secundina, a las seis nos alistábamos y cuando eran las seis y media estábamos en ese salón hasta las 5 de la mañana. ¿Qué qué hacíamos en tanto rato? ¡Bailar toda la noche! Eso era lo que hacíamos. Las fiestas empezaban a las seis de la tarde y al día siguiente eran las nueve de la mañana, y a las diez de la mañana suspendían el baile y hasta la 5 de la tarde, otra vez volvían y empujaban la mejenga. Así lo recuerda Pastor y así lo cuentan los abuelos de Potrero Grande. Había un salón de piso de tierra y otro de madera. En las fiestas hacían una música, que era con acordeón, con concertina bailaban. En esa época habían músicos, que eran sacados dentro de la misma gente. Ellos trataban con acordeones. La música la tocaban ellos mismos. El acordeón lo tocaba un señor que se llamaba Maximiliano Morales. Ponciano y Marcelino Morales, eran los músicos, que tocaban al estilo chiricano en esa época. Y para llevar los ritmos, los músicos tenían unas "cajas". Las cajas donde tocaban eran hechas de cuero de saíno. Ellos formaban una caja de cuero de saíno y al aporrear, daba como forma de una batería. Ellos mismos fabricaban sus instrumentos musicales. Puede ser hecho de un cajón de madera, pero la cuestión es que ellos lo forraban con cuero de animales, entonces le sacaban el ruido ahí, al acorde de la música. A veces venían músicos de otros pueblos y entonces sí se ponía bueno. Aquí apareció un músico que llamaban Román Quirós, que venía de Volcán. Eso era hace años. Pero mire, cuando se paraba la gente ahí, en el canto de una jarana, ahí y vían venir a un caballo blanco... Mire ese día no quedaba nadie en las casas. ¡Román Quirós tocando! Vieras, esas eran las fiestas buenas. El músico era el alma de la fiesta, ese era famoso, traía un bandoleón... Ese sí sabía tocar. Y prosigue 
doña Celina sacando vívidas imágenes de su memoria. Del bandoleón salían cumbias que se bailan sueltas... La cumbia se baila en círculo. También se bailaba el corrido, en parejas. Todavía me recuerdo que eso era lo que bailaba Natividad Beita. Mmm, no había alegría más grande del mundo que bailar el corrido. El corrido era ligero... la cumbia no, era dando vueltas. La mazurca y el vals... Viera que bonito cuando una pareja sabe bailar vals. Pero no es todo el que sabe bailar vals. Ellos eran expertos, panameños de allá, venían de allá y sabían bailar...

Sentado en un taburete, allá en su ranchito de Las Vueltas, cerca de Potrero Grande, Vicente Guerra, pelo blanco y perfil agudo, ríe y nos habla de los bailes. Yo tenía cuando eso... ¿no le digo? dieciocho años. De ahí en adelante fui a visitar esas fiestas. Sería entonces el año de 1946. También José Santos Concepción, pese a su avanzada edad, todavía se acuerda de aquellos bailes, sobre todo las cumbias, los puntos y los valses. Y doña Tomasa Nájera, de origen térraba, casada con don Julio Cedeño, chiricano de pura sepa que vive en Curré, es de la misma opinión: sí, el chiricano lo más que bailaba eran cumbia, pasillo y punto. Eso era lo que más se bailaba. No había de esa música de ahora. A veces era la misma música que se repetía una y mil veces, según la memoria y habilidad del musiquero. Era la misma música, sí es cierto, pero no se aburrían. Al menos eso dice Pastor Pinzón. Más bien le ponía más sabor, porque no importa si repetían, porque no tenían un repertorio así, grande, como decir que había gran abundancia de música, ¡no!. A veces se daba que cantaban la cocaleca infinidades de veces, pero diay, entonces ¡bailaban la cocaleca!"” Se conformaban... Que hubiera música durante toda la noche, la madrugada y al día siguiente... y la tomadera por todas partes, eso era. Y la noche seguía, y seguía al ritmo de la caja y el acordeón. Pero como muchos eran descalzos, y los pisos de madera, dice doña Celina, entre risas, que aquello sonaba cruak, cruak... Ver figura No. 6.

Pero los bailes, como todo en la vida, fueron cambiando. Cambiaron los ritmos y los instrumentos. Primero había el acordeón, después vino la guitarra, después vino la marimba y después vino la rocola y después viene "eso" que traen ahora (risas). Pero también las antiguas formas de bailar fueron desapareciendo para dar paso a otras nuevas. Luz Alba Chacón es una historiadora, oriunda de Buenos Aires y descendiente de chiricanos por parte de madre. Con cuánta alegría recuerda doña Luz aquellos bailes que vio cuando niña. Ver bailar era de por sí un espectáculo. Pero un día trabajadores de la bananera llegaron con nuevas formas de bailar. Venían vestidos a la moda y icon zapatos! Ya no bailaban en círculo la cumbia y el punto. Ahora solo en pareja, 
y ¡caramba! pegando la carita. Esto sucedía en Buenos Aires, a varios kilómetros de Potrero Grande. Pero al cabo del tiempo lo mismo ocurriría en Potrero. Poco a poco se imponían nuevas formas de baile en aquellas tierras sureñas. Sin embargo, todavía hoy, más de sesenta años después, doña Secundina Torres, añora aquellos bailes de los mayores, aquellos bailes de cuando había chiricanos, y chicha y acordeones. Ojalá hicieran unos bailes tradicionales, me dijeron que iban a hacer unos. Ay, pero vieras cómo me deseo que los traigan y los pongan, porque dicen que lo van a hacer para que la gente nueva, las muchachas nuevas ¡qué se yo! se den cuenta de la manera bailar de la gente de antes. Pero ¡ahhh pucha!... Rocío, mi hija, dice: "cochinada, qué voy a estar yendo yo a eso”, porque ahora la música típica, es cochinada de música, ¡eso no me gusta! ...es lo que dicen. ... ¡Pero qué bonito es recordar!

\section{Costarricenses de origen chiricano.}

Un día de 1964, Vicente Guerra decidió que tenía algo importante que resolver en la capital y tenía que hacerlo de una vez por todas. Vendió sus pertenencias y decidió irse para San José, al Registro Civil, a exigir su cédula y de paso aclarar un par de cosas con respecto a su identidad: ... lo único que tenía lo vendí para hacer la plata y pagar los pases y alquilar cuarto allí, y comer en San José, para ir al Registro Civil a decirles que yo necesitaba tener cédula y que es una mentira que nosotros somos panameños, porque las leyes civiles dicen que el que nace aquí, es costarricense, sin tener en cuenta cuál sea su origen, y yo soy nacido en Buenos Aires de Puntarenas. -No conozco Buenos Aires, me dijo el funcionario. ¿Es de Panamá o de Costa Rica? Buenos Aires es de Panamá, argumentó. -Que no, le dije yo, que es de Costa Rica. -No señor, que es de Panamá. -Bueno traigan un mapa, les dije. Búsqueme ahí donde dice Buenos Aires, a qué pertenece. Entonces él lo halló en la provincia de Puntarenas, en la Zona Sur. Entonces me dijo: usted tiene razón, usted es costarricense, usted nació aquí. Entonces se convenció y me dijo que sí tenía derecho a la cédula. Pero ahí ya yo tenía 36 años. Había perdido la mayor parte de mi vida y de mi juventud sin poder lograr hacer nada, porque si uno no tenía cédula no tenía derecho de escriturar una tierra, ningún préstamo de banco, así es que hasta entonces comencé yo a trabajar (comercialmente) a esa edad. Pero el pueblo entero nacido aquí estaba padeciendo la misma cosa. Y repite convencido de su triunfo... Buenos Aires no es de Panamá, nunca lo ha sido y ahora ya está establecido que pertenece a Costa Rica. Vicente Guerra Miranda, quien falleciera poco después de nuestra 
entrevista, representa a una generación de origen chiricano nacida en Costa Rica, que ostenta legítimamente su ciudadanía. Potrero Grande pertenece a Costa Rica, es cierto, pero se hizo con gente construida con retazos de las dos tierras y con el alma a ambos lados de la frontera. Con el tiempo fueron llegando meseteños: campesinos de Santa María de Dota, finqueros de Escazú, gente "de todos lugares y también de Puriscal", como dice la canción. Algunos se mezclaron con indígenas de la región, térrabas, y borucas principalmente. Pero que nadie dude dónde queda Potrero Grande, de Buenos Aires, un pueblo costarricense de origen chiricano panameño, clavado irremediablemente, en el corazón del Sur, fruto, como todo el sur, de muchas sangres, de muchas gentes.

\section{Integración de los chiricanos.}

Nuestra percepción es que todavía a mediados del siglo XX existía un entramado de culturas tradicionales en que interactuaban meseteños, indígenas y chiricanos. Este tejido se desestructura a partir de la construcción de la Carretera Interamericana, incursión masiva de meseteños, modernización e instauración del modelo reformista de la Segunda República. Como resultado de este proceso la identidad chiricana se ha vuelto cada vez más borrosa e imprecisa. Cabe agregar a estos factores el cese de la migración chiricana, la acción de los medios de comunicación de masas y por supuesto, el efecto de homogeneización ideológica y cultural causado por el sistema educativo. Hoy, la población de origen chiricano se ha integrado a la sociedad costarricense, muchos abuelos chiricanos han muerto o regresaron al otro lado de la frontera y sus nietos están plenamente insertos en la sociedad costarricense, la que por lo demás, no hace diferencias entre las personas de origen meseteño y las de origen chiricano. Los hijos y nietos de los chiricanos son costarricenses y muchos de ellos han perdido la noción de pertenecer a un grupo portador de una especificidad étnica o cultural. Por su parte, el costarricense promedio, tampoco tiene conciencia de que exista diferencia entre esta población y el resto de los costarricenses. Más aún, en el Valle Central, el término chiricano carece de significado. A pesar de ello, está en manos de los chiricanos actuales, fundamentalmente, determinar si es válido recuperar la conciencia de su origen étnico. Con esta investigación solicitado por Potrero Grande, esa comunidad ha dado un paso.

\section{Una nación costarricense para todos...}

Mucho se ha hablado durante los últimos años en círculos académicos de la "construcción de la 
nación”. Pienso que la tarea que nos queda por delante no es de discusión teórica, sino de acciones concretas que expliquen, difundan y pongan en valor, a los diferentes grupos étnicos que forman parte de la nación costarricense, con su vida, sus sueños, sus manifestaciones culturales, su realidad y su identidad. Aprovecho para dar las gracias al Instituto Costarricense de Electricidad, Proyecto Hidroeléctrico El Diquís, por esta valiosa oportunidad de contribuir a la indagación y el fortalecimiento de las identidades y las culturas del Sur de Costa Rica. A la UNED por haber cristalizado el producto de esta investigación en un libro, y a la comunidad de Potrero Grande, de Buenos Aires, Puntarenas, por haberse permitido la libertad de soñar y ejercer su derecho conocer su historia y fortalecer su identidad.

\section{BIBLIOGRAFÍA UTILIZADA}

Barboza, Mónica y Víctor Montero M.

2002. Propuesta metodológica para conocer la posición de la comunidad de Potrero Grande ante el Proyecto Hidroeléctrico Boruca. Costa Rica: Universidad de Costa Rica, seminario de graduación para optar por el grado de Licenciatura en Administración Pública.

Bozzoli, Ma. Eugenia.

1985 Desarrollo de la Región Brunca, tendencias y perspectivas. Revistas de Ciencias Sociales, No. 2.

1984 Desarrollo socioeconómico del cantón de Buenos Aires: tendencias 1973 - 1983. Documentos del Laboratorio de Etnología. UCR.

Bozzoli, Ma. Eugenia e Isabel Wing Ching

1979 Encuesta socioeconómica en la Zona del P.H Boruca. Universidad de Costa Rica. Instituto Costarricense de Electricidad.

Carmack, Robert

1994 Soplos de viento en Buenos Aires. Editorial UCR

Castillero R, Ernesto J.

1999 Historia de Panamá. Producciones Erlizca. 
1968 Ensayo de Monografía de la Provincia de Chiriquí. Sin editorial. Panamá

Chacón, Luz Alba

1986 Buenos Aires. Cantón de Puntarenas. Apuntes para su historia. Imprenta Nacional. San José

Figueroa, José María.

Tomado de notas mecanografiadas cedidas por el Lic. Hernán Gutiérrez (Trabajador Social).

García Contreras Manuel

1988 Apuntes geohistóricos de la colonización de la península de Osa (Costa Rica) Revista Geoistmo. 1988.

V. 2(1) p. 27-40.

González Beitia. Aura A.

2003 Huellas de la chiricanidad, ideario de panameñidad. Impresora Central. S A. David Chiriquí.

Gutiérrez Pablo

1983 La colonización agrícola del Valle del General 1850 - 1950 Tesis. Escuela de Historia. UNA

Instituto Costarricense de Electricidad

1980 Informe anual de labores 1980. Reubicación de Poblaciones P. H. Boruca.

1979 Informe anual de labores 1979. Reubicación de Poblaciones P.H. Boruca.

Jaén Suarez, Omar

1979 La población del Istmo de Panamá. Impresora de la Nación. Panamá.

Osorio Osorio, Alberto

1988 Chiriquí en su historia. (1502 - 1903) Tomos 1 y 2. Litografía Enan Panamá.

Sibaja Ch, Luis Fernando

1968 El límite sureste de Costa Rica. Tesis licenciatura. Facultad ciencias y letras. UCR.

1969 El conflicto bélico de 1921 entre Costa Rica y Panamá. Seminario de investigaciones centroamericanas. Departamento de Historia y Geografía. 
Indexaciones: Repositorio de Revistas UCR, DIALNET, Latindex, REDALYC Directorio y recolector de recursos digitales del Ministerio de Cultura de España, Directory of Open Access Journals.

Diálogos Revista Electrónica de Historia ISSN 1409-469X. Número especial 2008. Dirección web: http://historia.fcs.ucr.ac.cr/dialogos.htm

\section{FIGURAS}

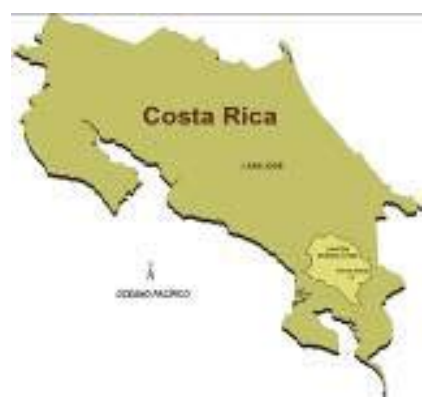

Fig.1

Ubicación de Potrero Grande.

Cantón de Buenos Aires, sur de Costa Rica.

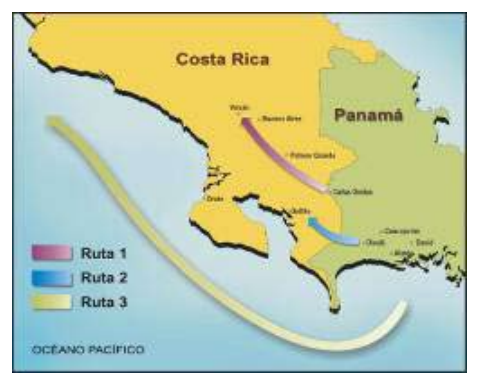

Fig. 2

Ingreso de chiricanos al territorio costarricense.

1. Cañas Gordas. 2. La Cuesta y 3. Vía marítima.

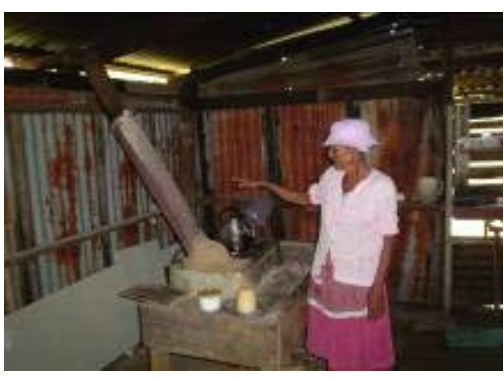

Fig. 3

Ella es fuerte como una palmera de la sabana. Inteligente y lúcida, Leonor Lezcano, aportó los nombres de los primeros colonos de Potrero Grande.

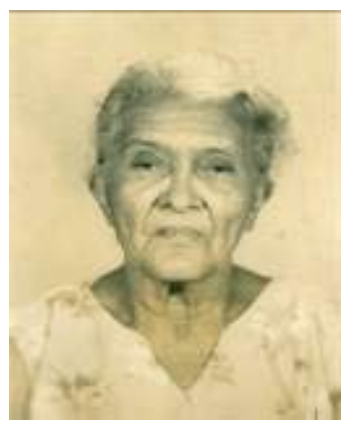

Fig. 4

Nieta de Juan Concepción, sabanero de los legendarios hermanos Guerra, Andrea Concepción todavía hoy es recordada como partera del pueblo. Recibía a los niños con frases como esta: "Mijito, ¡a trabajar a este mundo!”. 


\section{9) $9^{\circ}$ CONGRESO \\ o \& CENTROAMERICANO \\ d) UL IIIS IOIR}

-

Indexaciones: Repositorio de Revistas UCR, DIALNET, Latindex, REDALYC Directorio y recolector de recursos digitales del Ministerio de Cultura de España, Directory of Open Access Journals.

Diálogos Revista Electrónica de Historia ISSN 1409-469X. Número especial 2008. Dirección web: http://historia.fcs.ucr.ac.cr/dialogos.htm

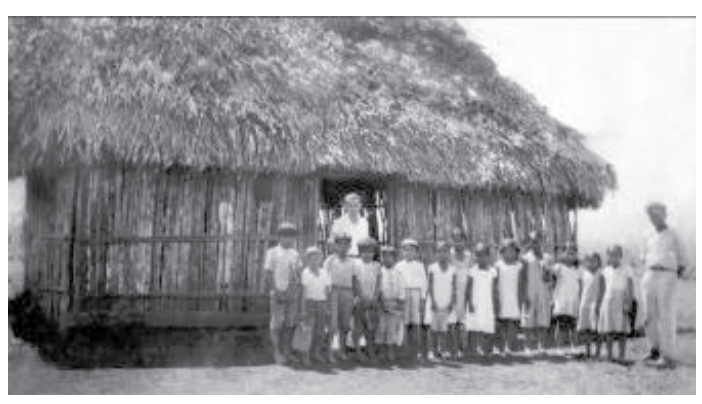

Fig. No. 5

Escuela de Potrero Grande construida en 1934 a la llegada del primer maestro, cuando todos los potrereños eran chiricanos. La escuela era un rancho tradicional de techo de palma y paredes de chonta.

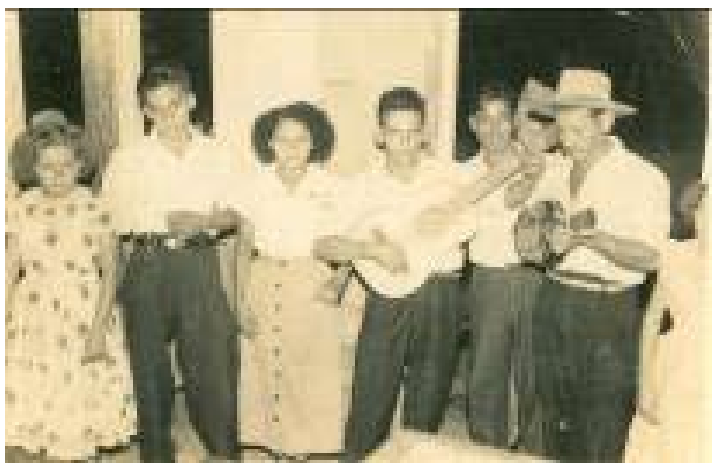

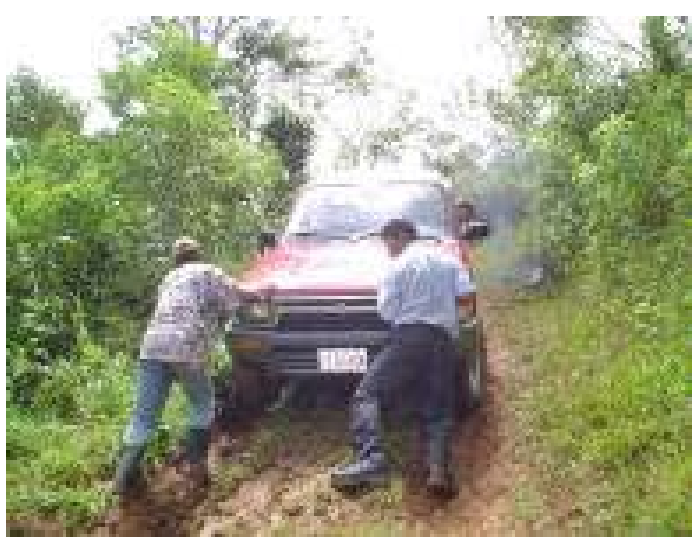

Fig. 7

Un día Pastor Pinzón (derecha), me dijo: "ponga esta foto, para que sepan que una investigación lleva un gran esfuerzo". Y me puse a pensar que a veces los procesos investigativos también se atascan...

Fig. 6.

Claro que amanecían las fiestas. Viera usté...

Y había cumbia, punto y pasillo. ¡Y el piso hasta que sonaba!! Enrique y Ovidio Alfaro tocan guitarra y bandolina. Rosita Rojas Pití (al centro). 